\title{
Phenotypical Classification of Type 2 Diabetes Mellitus
}

\author{
Nayana Devang ${ }^{1}$, Prabha Adhikari ${ }^{2 *}$ and Nandini $\mathbf{M}^{3}$ \\ ${ }^{1}$ Department of Medicine, Kasturba Medical College, Manipal University, Mangalore-575001, Karnataka, India \\ ${ }^{2}$ Department of Medicine, Yenepoya Medical College, Yenepoya University, Mangalore-575018, Karnataka, India \\ ${ }^{3}$ Department of Biochemistry, Kasturba Medical College, Manipal University, Mangalore-575003, Karnataka, India
}

Received: August 16,2018; Accepted: September 04,2018; Published: November 05,2018

*Corresponding author : Prabha Adhikari, Head Department of Medicine, Yenepoya Medical College, Mangalore-575018, Karnataka, India, Tel: +91 988099129; E-mail: prabha.raghuveer@gmail.com

\begin{abstract}
Obesity is believed to be the major contributing factor for type 2 diabetes. Obese subjects have 2-3 fold higher risk of developing type 2 diabetes. Obesity in type 2 diabetes increases the risk of hypertension, dyslipidemia and cardiovascular diseases. The current study was aimed to classify type 2 diabetic patients phenotypically based on the obesity indices and to study the prevalence of each phenotype.
\end{abstract}

Methodology: This study included 336 type 2 diabetic patients who attended Kasturba Medical College Hospital, Mangalore. Their waist circumference and body mass index were measured. Based on these measurements they were classified into four phenotypes as follows:

Generalized obesity: high values of waist circumference and body mass index.

Truncal obesity: high values of waist circumference and norma body mass index.

Non-obesity: Normal values of waist circumference and body mass index.

The details of glycaemic index, anti-diabetic drug usage, and diabetic complications exhibited were collected from case records.

Results: 71\% ( $\mathrm{n}=238)$ of type 2 diabetic patients had generalized obesity, $16 \%(n=54)$ of type 2 diabetic patients had truncal obesity, and $13 \%(n=44)$ of type 2 diabetic patients were non-obese/lean. There was no significant difference in the HbA1c level between obese and non-obese diabetics.

Conclusion: Among the three phenotypes of type 2 diabetes, generalized obesity appears to be the highly prevalent phenotype.

Keywords: Obesity; Type 2 diabetes mellitus; Phenotypical classification

\section{Introduction}

Diabetes has become a universal health issue that affects 425 million people around the globe [www.idf.org]. The main reason for increased incidence of type 2 diabetes mellitus (T2D) in developed as well as developing countries is the obesity epidemic. Obesity is thought to be the primary cause of T2D in people with genetic predisposition [1]. There is a parallel increase in the rates of T2D and obesity over the last 50 years.
Body mass index (BMI) and waist circumference (WC) are the two criteria that have been employed to classify obesity. BMI estimates total body fatness, while WC estimates visceral fat and risk of obesity-related disorders [2].

T2D subjects exhibit following phenotypes based on BMI and WC:

\section{T2D subjects with generalized obesity}

In generalized obesity fat is stored all over the body. Here subjects have fat body and fat limbs. They have higher values of WC and BMI. The causes are genetics, sedentary lifestyle and environmental causes [3].

\section{T2D subjects with truncal obesity}

In truncal obesity fat is primarily stored around the trunk of the body. Here subjects have fat body with thin limbs (centripetal obesity). It is also termed as abdominal obesity. Truncal obesity is said to be responsible for serious health conditions than generalized obesity. They have high WC but normal BMI. The causes are cushing's syndrome, hypothyroidism, metabolic syndrome and polycystic ovary syndrome [3].

\section{Non-obese T2D subjects}

The non-obese phenotype is characterized by disproportionally reduced insulin secretion and less insulin resistance, as compared with obese phenotypes. However, non-obese subjects have an increased risk of cardiovascular disease similar to obese subjects. They have normal WC and BMI. Causes are genetics, sedentary lifestyle, autoimmunity, stress, inflammation and fatty liver [4].

At present, there are no standard phenotypical classifications or definitions available for type 2 diabetes. A recent study of Richesson et al., compared the characteristics of T2D cohorts using heterogenous phenotype definitions but each of them identified different population of Duke University [5]. Considering the rapid increase in obesity in South Asia and the contribution of obesity to the development of type 2 diabetes, the present study classified the T2D patients to the three phenotypes based on obesity and assessed the prevalence of generalized and abdominal obesity among T2D patients attending Kasturba Medical College hospital, Mangalore. 


\section{Methods}

\section{Study Design}

This is a cross sectional study to find the prevalence of obesity in type 2 diabetic patients.

\section{Study Setting}

The study was conducted in the Department of Medicine, Kasturba Medical College hospital, Manipal University, Mangalore, Karnataka, India, after the study was approved by the Manipal University Ethics Committee.

\section{Participants}

It was a hospital- based cross-sectional study. 336 T2D patients aged 18-70 years were included after their written informed consent. The T2D was confirmed following the criteria of the American Diabetes Association: fasting blood sugar (FBS) $>126 \mathrm{mg} / \mathrm{dl}$, postprandial (PPBS) and random blood sugar (RBS) $>200 \mathrm{mg} / \mathrm{dl}$, glycated hemoglobin (HbA1c) level $>6.5 \%$. The cases with type 1 diabetes, malignancy, acute infections, inflammation, endocrine disorders like hypothyroidism, patients on insulin therapy, and chemotherapeutic agents, patients with confirmed neoplastic changes, old, sick and pregnant patients were excluded.

\section{Clinical assessment}

Clinical evaluation included measurement of height, weight and waist circumference. Their height (ht) and weight (wt) measurements were used to calculate BMI using the equation wt/(ht) ${ }^{2}$ [6]. The height was measured barefoot with head in horizontal plane to the nearest $0.1 \mathrm{~cm}$ using a graduated tape attached to the wall. The weight was measured in light clothes using a calibrated electronic weighing machine. WC was measured while standing at the level of umbilicus with a measuring tape [7] The details of mean blood HbA1c level, antidiabetic drugs used were collected from their case records. Diabetic complications such as retinopathy, neuropathy and ischemic heart disease were examined.

\section{Statistical Analyses}

The values of clinical parameters are represented as a mean \pm standard deviation. Frequencies are represented as percentage (\%). One way ANNOVA was used for the comparison of means. P value less than 0.05 was considered statistically significant.

\section{Results}

The prevalence of generalized obesity (71\%) was higher than the truncal obesity (16\%) and non-obesity (13\%) in T2D patients (Figure 1).

336 T2D patients were included in the current study with an average age of 58 years. The $71 \%(n=238)$ of T2D subjects had generalized obesity with high values of WC $(>80 \mathrm{cms}$ for females and $>90 \mathrm{cms}$ for males) and high values of BMI $\left(>23 \mathrm{Kg} / \mathrm{mt}^{2}\right)$. $16 \%(n=54)$ of T2D subjects had truncal obesity with high values of waist circumference $(>80 \mathrm{cms}$ for females and $>90 \mathrm{cms}$ for males), but normal values of BMI $\left(18-23 \mathrm{Kg} / \mathrm{mt}^{2}\right) .13 \%(\mathrm{n}=44)$ of the T2D subjects were non-obese who had neither generalized nor truncal obesity with normal values of WC $(<80 \mathrm{cms}$ for females and $<90 \mathrm{cms}$ for males), and normal values of BMI (18$23 \mathrm{Kg} / \mathrm{mt}^{2}$ ) (Table 1).

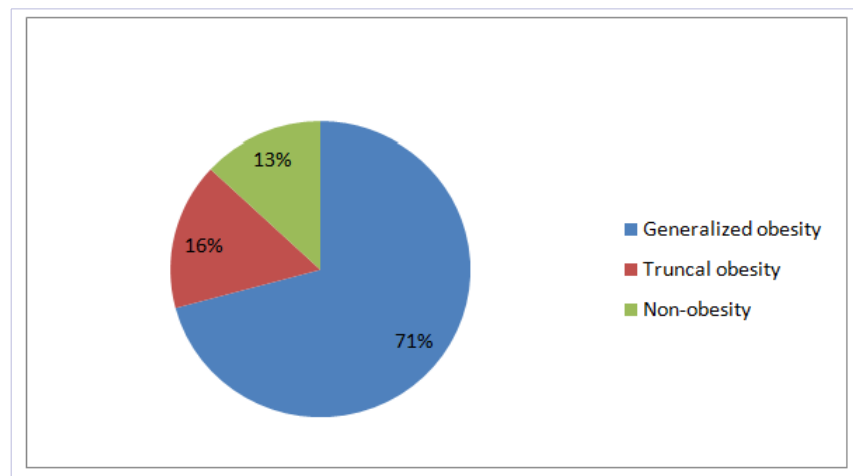

Figure 1: Prevalence of obesity in T2D patients

Table 1: Mean values of BMI and WC in obese and non-obese T2D subjects

\begin{tabular}{|c|c|c|c|}
\hline T2D & $\begin{array}{c}\text { Generalised } \\
\text { obesity (n=238) }\end{array}$ & $\begin{array}{c}\text { Truncal obesity } \\
(\mathbf{n = 5 4 )}\end{array}$ & $\begin{array}{c}\text { Non-obesity } \\
\mathbf{( n = 4 4 )}\end{array}$ \\
\hline $\begin{array}{c}\text { BMI (Kg/ } \\
\mathrm{mt}^{2} \text { ) }\end{array}$ & $27.9 \pm 2.78$ & $21.38 \pm 1.44$ & $20.93 \pm 1.43$ \\
\hline WC (cms) & \pm 10.77 & $88.12 \pm 4.55$ & $81.31 \pm 6.04$ \\
\hline
\end{tabular}

BMI, Body mass index; WC, Waist circumference; T2D, Type 2 diabetes

The mean values of glycaemic index (HbA1c) in obese and non-obese T2D patients are represented in figure 2 . The mean HbA1c levels in T2D patients with generalized obesity, truncal obesity and non-obesity were $9.79 \pm 3.8,9.65 \pm 3.44$ and $8.4 \pm 1.67$ respectively. Though, non-obese diabetics showed decreased trend in the mean HbA1c values compared to obese T2D patients, the decrease is not statistically significant $(p>0.123)$

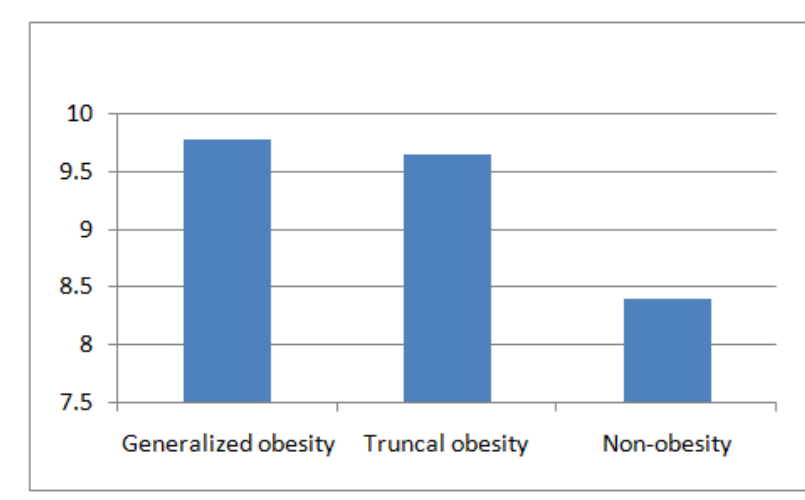

Figure 2: Mean HbA1c values

Table 2 shows the number of obese and non-obese diabetics on anti-diabetic drugs. The use of sulfonylurea and pioglitazone were higher in obese diabetics when compared to non-obese diabetic patients. The use of metformin and insulin were higher 


\begin{tabular}{|c|c|c|c|}
\hline \multicolumn{1}{|l|}{ Table 2: Anti-diabetic drugs usage } \\
\hline $\begin{array}{c}\text { Anti-diabetic } \\
\text { drugs }\end{array}$ & $\begin{array}{c}\text { Generalised } \\
\text { Obesity \% (n) }\end{array}$ & $\begin{array}{c}\text { Truncal } \\
\text { Obesity \% (n) }\end{array}$ & $\begin{array}{c}\text { Non-obesity } \\
\mathbf{\%}(\mathbf{n})\end{array}$ \\
\hline Metformin & $41(64)$ & $38(60)$ & $52(34)$ \\
\hline Insulin & $10(16)$ & $9(14)$ & $15(10)$ \\
\hline Sulfonylureas & $36(56)$ & $41(64)$ & $27(18)$ \\
\hline Pioglitazone & $13(20)$ & $12(18)$ & $6(4)$ \\
\hline
\end{tabular}

in non-obese diabetics when compared to obese diabetic patients.

Table 3 shows that the larger number of obese T2D subjects

\begin{tabular}{|c|c|c|c|}
\hline Table 3: Diabetes complications \\
\hline Complications & $\begin{array}{c}\text { Generalized } \\
\text { Obesity \% }\end{array}$ & $\begin{array}{c}\text { Truncal } \\
\text { Obesity \% }\end{array}$ & $\begin{array}{c}\text { Non- } \\
\text { obesity \% }\end{array}$ \\
\hline Retinopathy & 18 & 34 & 14 \\
\hline Neuropathy & 14 & 17 & 28 \\
\hline Ischemic heart disease & 28 & 28 & 9 \\
\hline
\end{tabular}

showed retinopathy and heart disease. While, higher number of non-obese T2D subjects showed neuropathy.

\section{Discussion}

Obesity may put a person's health at risk. This study demonstrates the high obesity rates among T2D patients in South India. In our study, the prevalence of generalized obesity and abdominal obesity were $71 \%$ and $16 \%$ respectively in T2D patients. Previously, Mugharbel et al. showed the prevalence of obesity to be 78\% in T2D subjects of Al Khobar [8]. An Indian study of Pradeepa et al. showed the prevalence of abdominal obesity to be $26 \%$ in Tamilians [3]. The rapid changes in socioeconomic life in the South Canara region including Mangalore with an increased energy intake and lower energy expenditure has led to obesity [9].

In India, there are no standard phenotypical classifications or definitions available for type 2 diabetes. Richesson et al., studied the phenotype definitions of American population with type 2 diabetes and showed significant differences across phenotypical definitions that vastly affect their implementation in medical diagnosis and patient care [5]. Indian T2D subjects exhibit both obese and non-obese phenotype. Our study focussed to classify the T2D patients based on the obesity with the belief that the appropriate phenotype classification enables selection of treatment option, health improvement, comparative analyses, and research.

Bae et al. reported the positive association of $\mathrm{HbA1c}$ with obesity in diabetic Americans [10]. Though, both obese and nonobese diabetics showed poor glycaemic control in our study, the obese T2D subjects showed higher trend in HbA1c value which may be due to the higher BMI and poor adherence among obese subjects.

The higher prevalence of heart disease in obese diabetic subjects of our study is in concordance with the previous study that reported higher incidence of coronary heart disease in obese diabetics [11]. However, our study showed higher prevalence of neuropathy in non-obese diabetics when compared to obese diabetics which may be due to the higher use of insulin suggesting sudden beta cell failure [12]. A study of Sutjahjo et al. reported the higher incidence of neuropathy among non-obese diabetic males [13]. Moreover, genetic factors may also determine the onset of diabetic complications in obese and non-obese subjects which needs to be elucidated $[14,15]$.

Our study utilised data of diabetics attending tertiary care hospital of Mangalore. It may not reflect the result of whole population. Future studies with larger sample size must include subjects from many states of India for accurate results.

Though the prevalence of non-obesity is lower than obesity among T2D patients, the severity of complications are alike in both forms and it is incorrect to believe the myth that "only fat people get diabetes" [16]. Non-obese patients must understand this to address the necessary prevention of the T2D risk.

\section{Conclusions}

Our study showed that the prevalence of generalized obesity was higher in type 2 diabetic South Indian subjects. Importantly, it appears that the T2D patients have a higher risk of developing diabetic complications irrespective of presence or absence of obesity.

\section{Acknowledgments}

We are greatly thankful to all the participants in this study and Manipal University for their collaboration in this study. ND is grateful to DST for funding the study.

\section{References}

1. Leong A, Porneala B, Dupuis J, Florez JC and Meigs JB. Type 2 Diabetes Genetic Predisposition, Obesity, and All-Cause Mortality Risk in the U.S.: A Multiethnic Analysis. Diabetes Care. 2016;39(4):539-546. Doi: $10.2337 / \mathrm{dc} 15-2080$

2. Zhang M, Zhao Y, Wang G, Zhang H, Ren Y, Wang B, et al. Body mass index and waist circumference combined predicts obesity-related hypertension better than either alone in a rural Chinese population. Sci. Rep. 2016;6:31935. Doi: 10.1038/srep31935

3. Pradeepa R, Anjana RM, Joshi SR, Bhansali A, Deepa M and Joshi PP. Prevalence of generalized \& abdominal obesity in urban \& rural Indiathe ICMR - INDIAB Study (Phase-I) [ICMR - INDIAB-3] Indian J Med Res. 2015;142(2):139-150. Doi: 10.4103/0971-5916.164234

4. Vaag A and Lund SS. Non-obese patients with type 2 diabetes and prediabetic subjects: distinct phenotypes requiring special diabetes treatment and (or) prevention? Appl Physiol Nutr Metab. 2007;32(5):912-920. Doi: 10.1139/H07-100

5. Richesson RL, Rusincovitch SA, Wixted D, Batch BC, Feinglos MN, Miranda ML, et al. A comparison of phenotype definitions for diabetes mellitus JAm Med Inform Assoc 2013;20(e2):e319-e326. Doi: 10.1136/amiajnl-2013-001952

6. Obel AO. Body mass index in non-insulin dependent diabetics in Kenya. Trop Geogr Med 1988;40(2):93-96. 
7. MaW-Y, Yang C-Y, Shih S-R, Hsieh H-J, Hung CS, Chiu F-C, et al. Measurement of waist circumference midabdominal or iliac crest? Diabetes Care. 2013;36(6):1660-1666.

8. Mugharbel KM and Al-Mansouri MA. Prevalence of obesity among type 2 diabetic patients in al-khobar primary health care centers. J Family Community Med. 2003;10(2):49-53.

9. Hillier TA, Pedula KL. Characteristics of an Adult Population with newly Diagnosed Type 2 Diabetes. Diabetes Care 2001;24(9):1522-1527.

10. Bae JP, Lage MJ, Mo D, Nelson DR and Hoogwerf BJ. Obesity and glycemic control in patients with diabetes mellitus: Analysis of physician electronic health records in the US from 2009-2011. Journal of Diabetes and its Complications 2016;30(2):212-220. Doi: 10.1016/j.jdiacomp

11. Samal KC, Das S, Agarwal BN, Panda NC, Tripathy BB. Nutritional status and profile of NIDDM of recent onset. J Diab Assoc India. 1998;28:99101.

12. George AM, Jacob AG and Fogelfeld L. Lean diabetes mellitus: An emerging entity in the era of obesity. World J Diabetes 2015;6(4):613620. Doi: 10.4239 /wjd.v6.i4.613
13. Sutjahjo A, Taniguchi $\mathrm{H}$, Hendromartono A, Baba S. High frequency of autonomic as well as peripheral neuropathy in patients with malnutrition-related diabetes mellitus. Diabetes Res Clin Pract 1988;5(3):197-200.

14. Murea M, Ma L and Freedman BI. Genetic and environmental factors associated with type 2 diabetes and diabetic vascular complications. Rev Diabet Stud 2012;9(1):6-22. Doi: 10.1900/RDS.2012.9.6

15. Devang N, Satyamoorthy K, Rai PS, Nandini M, Rao S, Phani NM, et al. Association of HSD11B1 gene polymorphisms with type 2 diabetes and metabolic syndrome in South Indian population. Diabetes Res Clin Pract 2017;131:142-148. Doi: 10.1016/j.diabres.2017.07.011

16. Arner P, Pollare T and Lithell H. Different aetiologies of Type 2 (noninsulin-dependent) diabetes mellitus in obese and non-obese subjects. Diabetologia 1991;34(7):483-487. 